\title{
Dramatic decline of the threatened Ili pika Ochotona iliensis (Lagomorpha: Ochotonidae) in Xinjiang, China
}

\author{
Li Wei-Dong and Andrew T. Smith
}

\begin{abstract}
The Vulnerable Ili pika Ochotona iliensis (Lagomorpha: Ochotonidae) is a poorly known mammal species that inhabits a restricted geographic range in the Tian Shan Mountains, Xinjiang Uygur Autonomous Region, China. It was discovered in 1983, described in 1986, and subsequently investigated over the following decade. As no studies were conducted on this pika during the next 10 years, a comprehensive census was undertaken in the summers of 2002 and 2003, including all sites where it had previously been observed. Evidence of the Ili pika was found at only 6 of 14 sites censused, and was extinct in two of six regions, including the type and paratype localities (Jilimalale Mountain). Ili pika populations appear to have declined in three of six
\end{abstract}

regions, and in only one region did the population appear to be comparable to a decade earlier. Like all rockdwelling pikas, the Ili pika has a low population density and rate of reproduction. Additionally, populations on its preferred habitat of cliff faces are highly fragmented. Increased temperatures, possibly due to global warming, and increased grazing pressure may have interacted with the normal population dynamics of the Ili pika to contribute to its recent dramatic decline. We recommend that the Ili pika's Red List status be changed from Vulnerable to Endangered.

Keywords China, Endangered species, global warming, grazing disturbance, Ili pika, Ochotona iliensis, Ochotonidae.

\section{Introduction}

The Ili pika Ochotona iliensis (Lagomorpha: Ochotonidae) is a poorly known mammal species that inhabits a restricted geographic range in the Tian Shan Mountains, Xinjiang Uygur Autonomous Region, China. This endemic species was discovered in 1983 and first described in 1986 (Li \& Ma, 1986) based on three specimens collected in 1983 and 1985. In the decade following its discovery a broad range of studies were conducted on the characteristics, habitat, distribution, population ecology, daily activity rhythm, reproductive biology, and feeding habits of the Ili pika (Li et al., 1988; Li \& Zhao, 1991; Li et al., 1991a,b; Li \& Turgan, 1992; Li et al., 1993a,b; Li et al., 1994; Li et al., 1995; Ma et al., 1996; Li, 1997).

The Ili pika (Plate 1) is brightly coloured with large rusty-red spots on the forehead and crown, as well as on the sides of the neck. It is a large pika (216.5-250 g), with ears $(36-37 \mathrm{~mm})$ and hind feet $(42-43 \mathrm{~mm})$ that are among the largest of the ochotonids. Ili pikas occupy

Li Wei-Dong Xinjiang Academy of Environmental Protection, 38 South Beijing Street, Urumqi, Xinjiang 830011, China

Andrew T. Smith (Corresponding author) School of Life Sciences, Box 874501, Arizona State University, Tempe, AZ 85287-4501, USA. E-mail a.smith@asu.edu

Received 25 March 2004. Revision requested 10 June 2004. Accepted 19 October 2004. slightly sloping high rock walls or cliff faces interlaced with a number of gaps or holes that serve as their dens. Ili pikas occupy solitary territories at low density. The species is characteristically asocial, and unlike most pika species it has not been observed to vocalize. Like other rock-dwelling pikas, it apparently has a low rate of reproduction (based on an observation of two young in a nest) (Li et al., 1993b; Li, unpubl. data).

The distribution of the Ili pika includes two branches of the Tian Shan Mountains, where it is found at altitudes of 2,800-4,100 m. Based on early surveys for Ili pikas, it is possible to estimate the largest possible extent of occurrence (geographic range) for the species as the northern branch of the Tian Shan (including the Borohoro, Ilianhapilga and Tianger mountains) from $82^{\circ} 21^{\prime}$ to $87^{\circ}$ $35^{\prime} \mathrm{E}$, and along an east-west extension of the southern Tian Shan from $80^{\circ} 55^{\prime}$ to $84^{\circ} 50^{\prime} \mathrm{E}$ (although it has only been located in one small region near the centre of this distribution; Fig. 1). In the southern Tian Shan it is likely that the south Muzate river valley forms the boundary between the Ili pika to the east and the large-eared pika $O$. macrotis to the west. The Ili pika is the only pika reported from the northern and southern branches of the Tian Shan Mountains. This maximum estimate of the extent of occurrence of the Ili pika is $<20,000 \mathrm{~km}^{2}$. However, slightly sloping rock walls, the habitat most suitable for the Ili pika, are found over only $17 \%$ of this area, and thus the potential total area of occupancy is restricted. 


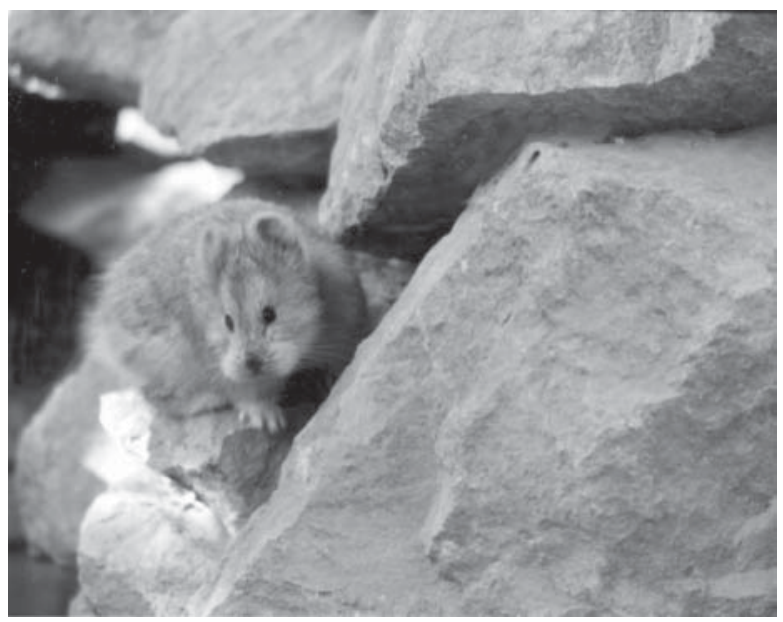

Plate 1 The Ili pika Ochotona iliensis in its characteristic cliff habitat.

There have been only 27 confirmed identifications of Ili pikas, including those collected as specimens, those collected to initiate a breeding colony (Li et al., 1993a; Li et al., 1994; Li et al., 1995), and those unambiguously identified in the wild (Li et al., 1991b; Li \& Turgan, 1992). In addition we know of 10 sightings of Ili pikas by local pastoralists. Approximate calculations based on the relative density of the species and the ratio of suitable habitat that it occupies throughout its range indicate that the total population number in the early 1990s may have been c. 2,900, with only c. 2,000 mature individuals. In addition to this low population size, the habitat occupied by the Ili pika is severely fragmented. On the basis of these data the Ili pika was first categorized as Vulnerable on the IUCN Red List in 1996, and retains this category on the most recent Red List (IUCN, 2003).
The purpose of this study was to re-examine the population status of the Ili pika, as it had been over 10 years since any field studies were conducted on the species. We examined all localities where Ili pikas were found during our first 10 years of investigation and searched suitable habitat to locate additional populations.

\section{Methods}

The field research team of 3-10 investigators comprehensively censused all known populations of the Ili pika and one additional site, including travelling $247 \mathrm{~km}$ on foot and horseback in habitats suitable for Ili pikas. Field exploration included 37 days in seven separate trips between 14 June and 2 September 2002, and 8 July and 24 September 2003. Twelve sites in five general regions in the northern spur of the Tian Shan and two sites in one region along the southern range of the Tian Shan were investigated (Fig. 1). The northern Tian Shan included the following mountains, regions and sites: (a) Borohoro Mountains, Jilimalale region (Nilka County; sites 1-3; Fig. 1) including the type and paratype localities, and Jipuk region (Jinhe County; sites 4-6). (b) Illianhalpilga Mountains, Bayingou region, Bayingou (Usu County; site 7) and Jingohe (Shawan County; site 8), and Hutubi South Mountain region, Qurgo Valley (site 9) and Qirenbulunhu (Hutubi County; site 10). (c) Tianger Mountains, Tianger Apex region, \#1 Glacier (Urumqi County; site 11) and Shengli Daban south (Hejing County; site 12). Along the southern Tian Shan, two sites were censused in the region of Telimati Daban (Kuqa County; sites 13-14). Surveys were expanded at Jilimalale Mountain, Jingohe and Bayingou beyond those areas censused in the first

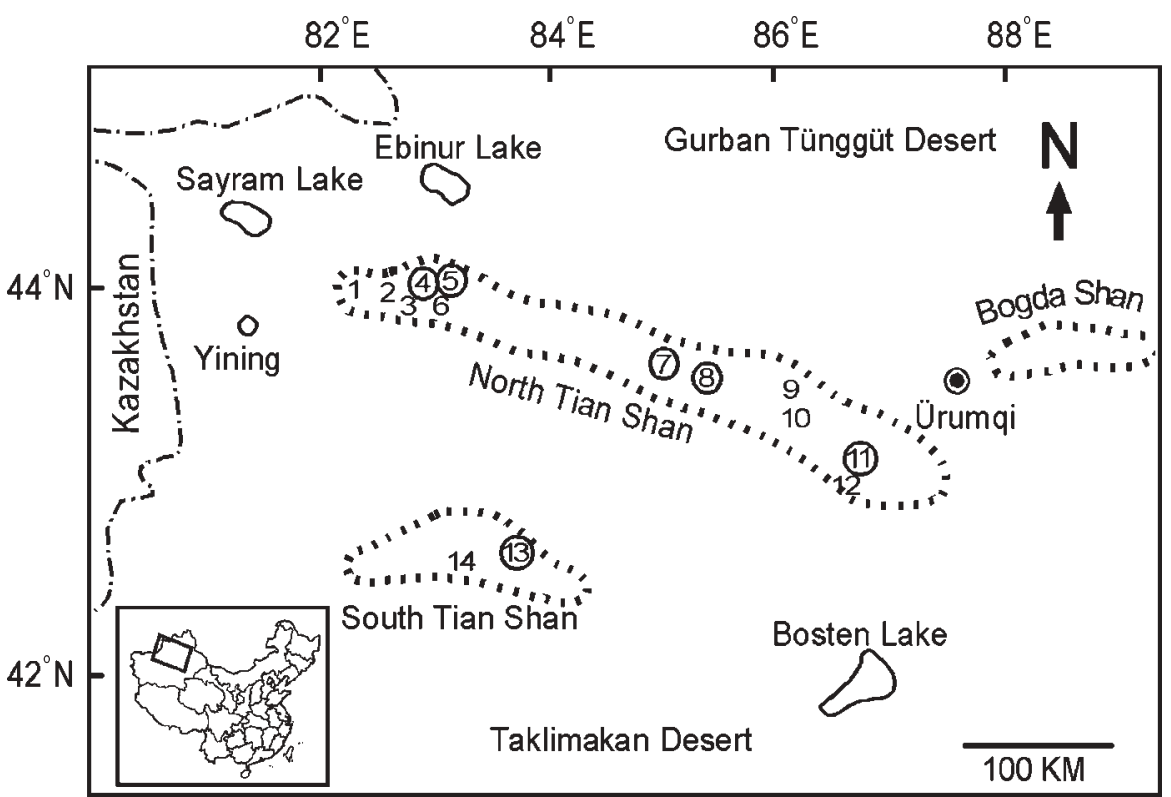

Fig. 1 Geographic range (dashed lines are maximum extent of occurrence) of the Ili pika Ochotona iliensis in the Tian Shan Mountains of north-western Xinjiang Uygur Autonomous Region, China. Numbers indicate study sites, and circled sites indicate apparently extant populations (see text for details): 1 , Jilimalale mountain west (type locality); 2, Jilimale mountain central; 3 , Jilimale mountain east (paratype locality); 4, Jipuk mountain east \#1;5, Jipuk mountain east \#2; 6, Jipuk mountain south; 7, Bayingou; 8, Jingohe; 9, Qurgo valley; 10, Qirenbulunhu; 11, \#1 Glacier; 12, Shengli Daban; 13, Telimati Daban north; 14, Telimati Daban south. 
decade of work on the species. The one new site investigated was at Qirenbulunhu. Three sites were revisited in summer 2003, Bayingou and the two sites in the Tianger Apex (\#1 Glacier and Shengli Daban).

The immediate goal was to determine the general status of the Ili pika at each site and region. We concentrated our observations on habitat types preferred by Ili pikas, looking for direct sightings or signs of their presence. Pikas deposit characteristic spherical faeces, deposit urine on stones in caves, store vegetation in hay piles, and leave distinctive tracks in snow. Survey results from the present study were compared with field notes from investigations conducted between 1983 and 1992. To ensure consistency one of us (LWD) participated in all surveys conducted on the Ili pika between 1983-1992 and 2002-2003. With the exception of the new Qirenbulunhu site, the surveys in 2002 and 2003 focused intensively on sites where Ili pikas had been recorded previously to determine as accurately as possible their change in status over the past decade. In addition, we recorded any changes in the habitat and the physical or anthropogenic factors that may have led to these changes, for comparisons with the conditions encountered during the first 10 years of investigations.

\section{Results}

No Ili pikas were observed during our surveys. The presence of pikas as indicated by signs varied among sites. We failed to find any fresh signs of pikas at eight of the 14 sites: Telimati Daban south, Shengli Daban south, Qurgo Valley, Qirenbulunhu, Jipuk Mountain south, Jilimalale Mountain west (the type locality), Jilimalale Mountain central, and Jilimalale Mountain east (the paratype locality; Fig. 1).

Ili pikas were not found in two regions, Jilimalale (three sites) and Hutubi South Mountain (Qurgo Valley and Qirenbulunhu sites). Jilimalale Mountain (Flat-top Mountain) extends approximately $20 \mathrm{~km}$ from west to east. We thoroughly searched across the entire reach of Jilimalale, concentrating our efforts in the areas where pikas had been found previously, but also searching for new sites in appropriate habitat. There were no fresh signs of any type. The only urine deposits that we encountered appeared old, and no pika faeces were found in areas where they were commonly distributed in the past. It appears that the Ili pika disappeared from this area a number of years previously. Signs of prior occupation by pikas were found at the new site, Qirenbulunhu, although none was fresh and it appeared that pikas had disappeared from this site also.

In three regions, Jipuk (two eastern sites), Tianger Apex (\#1 Glacier site), and Telimati Daban (northern site), we were able to find some fresh pika signs, although they were sparsely distributed, not found at all habitats suitable for occupation by Ili pikas, and not as abundant and numerous as in the past. Our survey thus indicates that pikas in these areas have declined since the time of our earlier censuses.

In only one region, Bayingou (Jingohe and Bayingou sites) were there signs of presence (considerable stored hay and fresh faeces) abundant and equal to earlier censuses of the Ili pika. Unfortunately, the weather and visibility at the time of our censuses were poor and we were thus unable to locate any living pikas.

Populations of the Ili pika do not appear to have increased in any of the regions surveyed compared to their abundance a decade ago, and they have disappeared in two regions and declined in the remaining three. Ili pikas have disappeared from 57\% (8/14) of previously occupied sites. Taking into consideration the overall area encompassed by the sites censused, we estimate that the area of occupancy for the Ili pika has decreased from about $17 \%$ to $7 \%$ of the maximum potential extent of occupancy within the past decade.

\section{Discussion}

At the time the Ili pika was discovered and named, it occupied a restricted geographic range, was highly fragmented, and occurred at a low density. Nevertheless, it was possible to observe animals in the wild and capture them for $e x$ situ studies. In contrast, our recent censuses failed to make any sightings of the Ili pika, and based on the presence of the characteristic signs of pikas we found only one region (Bayingou), where the Ili pika population may not have declined. The species could not be found at two regions (including at the type locality on Jilimalale mountain), and apparently it has declined drastically at other regions throughout its range. In addition to our census, a decline or disappearance of the Ili pika has been noted by other surveys in the region. During the past 40 years more than 10 teams of medical workers and biologists have conducted thorough investigations on the epidemiology of plague in the region occupied by the Ili pika. These teams have concentrated on the mammal fauna and have not found any Ili pikas for many years. In summer 1994, Nikolai Formozov of Moscow State University attempted to locate Ili pikas at Shiling Daban (=\#1 Glacier, Tianger Apex), but was unsuccessful. Only the local pastoralists occasionally see an Ili pika.

There has been speculation that the Ili pika may have occupied a third mountain chain in the region, the Dzungarski Alatau Mountains (Shnitnikov, 1936; Smith et al., 1990). Formozov (2000) conducted extensive field work in this region and re-evaluated this situation. He concluded that the Ili pika currently does not occur in 
this area and was probably never found there. Formozov believes that Shnitnikov (1936) mistook the haystores of the commonly found silver mountain voles Alticola argentatus to be those of pikas.

We conclude that the population of the Ili pika has never been large and has recently decreased. Why has the Ili pika declined so dramatically in the past 10 years, and what are the consequences of this decline? Disease, particularly plague, is one possible cause of the decline. There has been considerable activity by Chinese research teams in the region, concentrating on the occurrence of plague in a sympatric species, the gray marmot Marmota baibacina. These investigations ruled out any possibility that the Ili pika has served as a reservoir for plague in the region (Li et al., 1991b).

Human activity and animal husbandry could have had a negative influence upon Ili pika populations. In the past no domestic livestock were grazed at elevations $>3,000 \mathrm{~m}$ in the region. Now, with increasing human population pressure, pastoralists commonly graze their sheep and horses at higher elevations in the Tian Shan. The livestock not only eat alpine vegetation, thus competing with pikas, but dogs accompanying the pastoralists and their herds may also catch pikas.

A third possible influence on the decline of pikas could be global climate change. In the Tian Shan Mountains of Xinjiang, glaciers are receding at an increasingly rapid rate and the altitude of permanent snow is rising, apparently in response to increasing temperatures in the region (Li \& Yi, 1988; Hu et al., 1993; unpubl. data from the monitoring station managed by the Chinese Academy of Sciences at our site \#11, Fig. 1). This rise in temperature could be linked with global climate change caused by anthropogenic factors. The Ili pika is an animal that lives in high, cold areas, and apparently since the Glacial Epoch of the Quaternary this species has gradually retreated to higher elevations on mountain tops, as has been reported for other pika species (Hafner, 1993; Yu et al., 2000). At Jilimalale Mountain the pikas have nowhere to go if increasing temperatures force them to live higher on the mountain. At the top of their cliff-face habitat is an expansive flat pasture, now occupied by pastoralists, their livestock and dogs, effectively blocking any vertical migration by pikas.

We conclude that the Ili pika may be influenced in the same way as in the model presented by McDonald \& Brown (1992), who investigated the potential changes of the mammalian fauna of isolated mountain top islands in the Great Basin of the United States due to global warming. They predicted that anticipated changes in temperature would drive alpine species farther up mountains, where there would be concomitantly less habitat, causing widespread extinctions of species in the current fauna. The first evidence of this effect for pikas has now been reported by Beever et al. (2003). Seven of 25 populations of American pikas Ochotona princeps in the Great Basin have been lost during this century, and Beever et al. (2003) stated that '. . . warmer temperatures seem likely to be contributing to apparent losses that have occurred at a pace significantly more rapid than that suggested by paleontological records.' Others have generalized this result more strongly: 'American pikas may unfortunately be the 'canary in the coal mine' when it comes to the response of alpine and mountain systems to global warming' (WWF, 2003). Similarly, in the Yukon, collared pika O. collaris populations have collapsed following uncharacteristically warm winters with limited snow cover (Franken, 2002; D. Hik, unpubl. data). The Ili pika may represent another case study of this phenomenon.

Rock-dwelling pikas in general (Smith, 1988; Smith et al., 1990), and Ili pikas in particular (Li \& Zhao, 1991; Li et al., 1991; Li, 1997), are poorly suited to counter local population extinctions. Rock-dwelling pikas tend to occur at low density, have low reproductive rates, and exhibit poor vagility, and thus small populations are subject to stochastic extinction events. The potential compounding effects of global warming and grazing by pastoralists may only speed up these processes. The highly fragmented cliff-face sites occupied by Ili pikas are unlikely to be rescued (sensu Brown \& Kodric-Brown, 1977) by colonization from nearby populations. Thus, loss of a pika population at one site may contribute to a downward spiral of regional (or metapopulation) extinction processes (Smith \& Gilpin, 1997). That Ili pikas have disappeared from more than half of the sites where they were originally recorded 10-20 years ago indicates that the species may be undergoing a rapid extinction.

The Ili pika is currently categorizied as Vulnerable on the Red List (IUCN, 2003). The results of our survey indicate that its categorization should be changed to Endangered according to criteria $\mathrm{A} 2 \mathrm{abc}$ and $\mathrm{C} 2 \mathrm{a}(\mathrm{i})$ (IUCN, 2001). This proposed change in categorization follows from the species' decrease in population size, extent of occurrence, and area of occupancy in the recent past. Additional research is needed to further document the distribution and abundance of the Ili pika, as well as to formulate a plan for the recovery of the species.

\section{Acknowledgements}

This research was supported by China Exploration and Research Society, Fauna \& Flora International, and the Xinjiang Ecology Society. Students of the \#2 Middle School in Urumqi and the Xinjiang Children's School of the Chinese Academy of Sciences, as well as the some alpinists and explorers from Urumqi, all joined in the field research. Field research was also supported by the Sanitary and Anti-epidemic Station of Ili Prefecture, Usu 
City, and Nilka and Shawan Counties. Xie Yan, Institute of Zoology of the Chinese Academy of Sciences, provided background reference materials. Xuemei Liu translated the article from Chinese, and William Bleisch and Yingyi Zhang provided helpful editing of the English text. Sarah Boyle and David Hik kindly commented on the manuscript.

\section{References}

Beever, E.A., Brussard, P.F. \& Berger, J. (2003) Patterns of apparent extirpation among isolated populations of pikas (Ochotona princeps) in the Great Basin. Journal of Mammalogy, 84, 37-54.

Brown, J.H. \& Kodric-Brown, A. (1977) Turnover rates in insular biogeography: effect of immigration on extinction. Ecology, 58, 445-449.

Formozov, N.A. (2000) Is the rarest pika (Ochotona iliensis) found in the Dzungarsky Alatau Ridge? Selevinia, 1996/1997, 235-238. [in Russian]

Franken, R.J. (2002) Demography and metapopulation dynamics of collared pikas (Ochotona collaris) in the southwest Yukon. MSc thesis, University of Alberta, Edmonton, Canada.

Hafner, D.J. (1993) North American pika (Ochotona princeps) as a Late Quaternary biogeographic indicator species. Quaternary Research, 39, 373-380.

Hu, R., Yang, C., Ma, H., Jiang, F. \& Urkunbek (1993) Glaciers and lakes in the Tian Shan Mountains and regional climate trends. Arid Land Geography, 17, 1-9. [in Chinese]

IUCN (2001) 2001 Categories and Criteria (Version 3.1). IUCN, Gland, Switzerland [http:/ /www.redlist.org/info/ categories_criteria2001.html, accessed 21 October 2004].

IUCN (2003) 2003 IUCN Red List of Threatened Species. IUCN, Gland, Switzerland [http:/ / www.redlist.org, accessed 1 September 2004].

Li, W. (1997) An endangered species of Lagomorpha - Ili pika (Ochotona iliensis). Chinese Biodiversity, 5 (supplement), 23-28. [in Chinese]

Li, W., Hamit, X. \& Ma, J. (1995) A preliminary observation on the pelage and seasonal molt order of Ili pika (Ochotona iliensis). Chinese Journal of Zoology, 29, 37-38. [in Chinese]

Li, W., Li, H., Hamit, X. \& Ma, J. (1988) First report on ecological study of the Ili pika (Ochotona iliensis). In Abstracts, Symposium of Asian-Mammalogy (eds A.T. Smith, R.S. Hoffmann, W.Z Lidicker, Jr. \& D.A. Schlitter), unpaginated. American Society of Mammalogists \& Mammalogical Society of China, Beijing, China.

Li, W., Li, H., Hamit, X. \& Ma, J. (1991a) A preliminary study on the distribution and habitat of Ochotona iliensis. Chinese Journal of Zoology, 26, 28-30. [in Chinese]

Li, W., Li, H., Hamit, X, Ma, J. \& Zhao, W. (1993a) Preliminary research on the daily activity rhythm of the Ili pika. Arid Zone Research, 1, 54-57. [in Chinese]

Li, W., Li, H. \& Ma, J. (1993b) A preliminary exploration of the reproductive biology of the Ili pika. Chinese Journal of Vector Biology and Control, 4, 120-122. [in Chinese]

Li, W. \& Ma, Y. (1986) A new species of Ochotonidae, Lagomorpha. Acta Zoologica Sinica, 32, 375-379. [in Chinese]
Li, W., Ma, J. \& Hamit, X. (1994) Preliminary research on the artificial feeding of the Ili pika. Chinese Journal of Vector Biology and Control, 5, 130-133. [in Chinese]

Li, W. \& Zhao, W. (1991) The component species of Genus Ochotona and its distribution areas in Xinjiang. Chinese Journal of Vector Biology and Control, 2, 305-308. [in Chinese]

Li, W., Zhao, W., Hamit, X. \& Ma, J. (1991b) A preliminary study on the ecology of the Ili pika and its relationship with the plague natural foci. Chinese Journal of Vector Biology and Control, 2, 202-205. [in Chinese]

Li, W. \& Turgan (1992) A report on new distributional data for the Ili Pika (Ochotona iliensis). Chinese Journal of Vector Biology and Control, 3, 22. [in Chinese]

Li, Z, \& Ye, B. (1988) Ten years of progress in the Tian Shan glaciological station. Journal of Glaciology and Geocryology, 20, 280-286. [in Chinese]

Ma, Y., Zhang, G. \& Zhumahaz (1996) Some biological data about the Ili pika. Arid Zone Research, 13, 3. [in Chinese]

McDonald, K.A. \& Brown, J.H. (1992) Using montane mammals to model extinctions due to global change. Conservation Biology, 6, 409-415.

Schnitnikov, V N. (1936) Mammals of the Semirechye. Nauka, Moscow and Leningrad, Russia. [in Russian]

Smith, A.T. (1988) Patterns of pika (Genus Ochotona) life history variation. In Evolution of Life Histories: Theory and Patterns from Mammals (ed. M.S. Boyce), pp. 233-256. Yale University Press, New Haven, USA.

Smith, A.T., Formozov, A.N., Hoffmann, R.S., Zheng, C. \& Erbajeva, M.A. (1990) The pikas. In Rabbits, Hares and Pikas: Status Survey and Conservation Action Plan (eds J.A. Chapman \& J.A.C. Flux), pp. 14-60. IUCN, Gland, Switzerland.

Smith, A.T. \& Gilpin, M.E. (1997) Spatially correlated dynamics in a pika metapopulation. In Metapopulation Dynamics: Ecology, Genetics, and Evolution (eds I.A. Hanski \& M.E. Gilpin), pp. 407-428. Academic Press, San Diego, USA.

WWF (2003) Disappearance of North American mammal linked to global warming. Focus, 25, 3 .

Yu, N., Zheng, C., Zhang, Y. \& Li, W. (2000) Molecular systematics of pikas (Genus Ochotona) inferred from mitochondrial DNA sequences. Molecular Phylogenetics and Evolution, 16, 85-95.

\section{Biographical sketches}

Li Wei-Dong is a member of the IUCN/Species Survival Commission Lagomorph Specialist Group and specializes in field investigation of the status of mammals and the conservation biology of lagomorphs, wild camels and chiru in western China.

Andrew Smith is Chair of the IUCN/Species Survival Commission Lagomorph Specialist Group and has worked on pikas in western China since 1984 . His research interests include behavioural ecology, metapopulation dynamics and the population biology of mammals. 